\title{
Individual adaptation of targeted advertising to digital environment
}

\author{
Igor Petrov ${ }^{1, *}$, Maxim Zemtsov ${ }^{1}$, Daria Bokareva $^{1}$ and Andrey Ivashchenko $^{2}$ \\ ${ }^{1}$ Vyatka State University, 36, Moskovskaya str., 610000, Kirov, Russia \\ ${ }^{2}$ Moscow State University of Civil Engineering, 26, Yaroslavskoye Shosse, 129337, Moscow, Russia
}

\begin{abstract}
The study is discussing the method of increasing the effectiveness of targeted advertising. Targeted advertising is the most popular form of advertising on social networks. The key element of the method is the formation of content considering the typological characteristics of the individual. The key problem that is solved by this method is increasing consumer loyalty to the brand or product through the formation of a perception of the value of the product. Perception of product value is formed by adapting advertising content and reaction to consumer actions. The characteristics of metrics for assessing the effectiveness of discretization of the audience of targeted advertising are given. The methodology of forming an individualized marketing strategy in the context of the differentiation of consumers specified in the article is discussed. Conclusions are drawn about the applicability of the proposed method for a traditional and digital sales channel.
\end{abstract}

\section{Introduction}

Modern economic development trends are changing the vision for the key elements of product formation. The modern principles of digital marketing distinguish as a separate element the digital transformation of product presentation, product advertising and feedback analytics [1-3]. Any marketing research is a special case of analytics and therefore is not allocated as a separate element.

Advertising efficiency is the key to any business. Various methods are aimed at solving this problem. From consumer research to building business models. Consumer understanding is the key to any business model. The business model allows you to systematically look at the organization of the business, track the migration of value in the event of a change in technology, the appearance of new products, or changes in consumer requirements. The task of consumer research, value proposition and competent construction of advertising communications all this requires an individualized approach to each buyer.

\footnotetext{
${ }^{*}$ Corresponding author: soft.rosko@mail.ru
} 


\section{Materials and Methods}

The current technological revolution has highlighted the digital environment and additive technologies as a key object. Therefore, digital media channels are essential for consumer products.

The last 4 years, the structure of sales channels has changed significantly. Instead of grocery retail, the advantage in customers is realized in digital sales channels through social networks and digital trading platforms. The largest audience reach in Russia is achieved through social networks, therefore, social networks are chosen as the target.

For the customer's as an object of consumption of industrial values from an industrial company, the digital environment is only a channel for promotion and sales. Therefore, assume that any information about the product and the user's actions to acquire it is formalized in the form of a set of discrete information messages with some content.

Consider the value proposition canvas [5] for content, see Figure 1., which has the following characteristics

- Using the consumer profile, you refine your understanding of the consumer.

- A value map shows how you intend to create value for this consumer.

- You achieve compliance if both sides are aligned with each other.

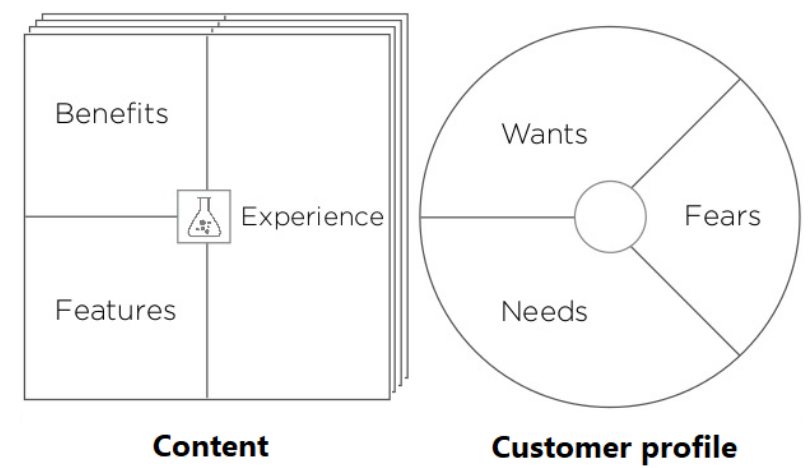

Fig. 1. Caption of the Figure 1. Below the figure.

As can be seen from the figure, one of the important factors in the formation of consistent content is the way feedback is implemented. In the case of the digital environment, receiving feedback from the consumer of the content is in most cases impossible or difficult.

The disadvantage of this approach is the lack of a position for highlighting the target group for the product. This approach involves individualization of the product by individual and subsequent scaling using the digital market environment of similar individuals. In the situation of regionalization of markets, there is a significant decrease in the volume of the regional product market. In such a situation, it is necessary to look for an approach to scaling the product through discretization of the user experience of the audience and consider different audiences in the product.

One of the tools for discretizing the user experience of an audience is typology [6-7] and socionics[8-9].

The purpose of the article is to generalize the experience of discretizing content into socionic groups to increase the effectiveness of targeted advertising.

Digital advertising is a type of content. The content-oriented approach to the analysis and formation of advertising allows us to draw an analogy with the process of assimilation of content and the reaction to it in e-learning. The format of e-learning, as well as the 
factors and principles of instruction in the case of non-linear educational courses, was described by the authors in patent[10].

The similarity with advertising and educational content in the digital environment allows us to highlight the psychological characteristics that are present when consuming any kind of content.

A distinctive feature of advertising as a type of content is the free nature of the reverse interaction with content.

The study of the nature of the interaction of the type of personality with content has been carried out over the past 8 years as part of knowledge management courses. The total audience reach in the analysed sample was 347 people. The study examined the nature of the perception of content, depending on the sociotype. The study was conducted by listening and testing students.

\section{Results}

As a result of the analysis of the perception of content in the course of a distance educational experiment, it can be distinguished that each group of content consumers with the same psychological characteristics perceives each property of the product differently for its application as an instrument to achieve its own goals.

At the functional level, consumers try to complete a specific task or solve a specific problem. For example, trim the lawn, eat right, write a report or provide professional assistance to your clients [11].

The study shows that consumers in solving problems rely on the typological functions of "Intuition-Sensing" and "Thinking-Ethics". These functions of the human psyche are responsible for collecting information and for making decisions. Such functions work in pairs: Intuition- Thinking, Sensing- Thinking, Intuition-Ethics, Sensory-Ethics.

The analysis of the experiment allows us to distinguish the following consumer groups and their goal setting:

- sensing thinking (ST): a group of consumers for which it is necessary to give quantitative measures for assessing the claimed effects, as well as methods for their verification;

- sensing ethics (SF): a group of consumers for which it is necessary to give quantitative and qualitative results achieved through the use of the claimed effects;

- intuition ethics (NF): a consumer group for which it is necessary to compare the various effects claimed and their assessment on a person or society;

- intuition thinking (NT): a group of consumers for which it is necessary to provide methods for comparing the claimed effects with analogues, as well as a description of the claimed effects.

At the social level, consumers try to look good, to achieve influence or a certain status in society. These tasks are associated with the formation of the image of a person in the eyes of others. For example, the image of a trendy consumer or a respectable professional.

An educational experiment revealed that the following combination of preferences "extraversion - introversion" and "judging - prospecting" solve social problems from a typological perspective; they determine the public appearance of a person. These pairs of preferences indicate how often we come in contact with the outside world and how we make these contacts.

Consumers most often have to deal with factors such as practical actions, people, places and objects. In the interaction of the client with extraversion or client with introversion can be detected relatively quickly, depending on its behavior and the nature of the interaction. For example, whether he seeks to immediately throw out a whole stream of information on you or is inclined to listen to your story about the product. 
In a digital environment, the manifestation of a social position is revealed through the intensity of reference communication and the stability of the reactive effect on the content. Adapting these factors to targeted advertising on social networks, we can distinguish the following features of this interaction:

- judging extroversion: consistent viewing and reaction to content with a stable in intensity and volume of audience reference;

- prospecting extroversion: uneven in the volume and intensity of the content reference, constant in reaction stability of interaction with the content;

- prospecting introversion: selectivity by reference audience volume, stability and intensity of interaction with content;

- judging introversion: selectivity in terms of audience size and stability of the intensity of interaction with content.

On an individual level, consumers tend to achieve certain emotional states, such as a sense of calm or security. For example, a consumer tries to make sure his investment is reliable or to get a job guarantee.

A similar character of the consideration of behavior is present in the typology. Personally-emotional tasks can be considered through stress tolerance assessments and communication styles. All these assessments are directly related to the personal situational context in which this or that consumer is located.

For a digital environment, the level of individuality of the content consumer affects the type of interaction with the content or the type of content, as well as the tonality of the content rating.

In the case of an increase in the level of stress resistance, an avalanche-like change in the type of interaction with the content occurs. A decrease in the level of stress tolerance leads to a strong change in the tonality of the assessment of content depending on personal experience with similar content.

The benefits are the results and benefits that the consumer wants. The benefit may be necessary, expected, or desirable for the consumer, but may also be unexpected. Benefits include functional convenience, social benefits, positive emotions, and cost savings. The study showed that the perception of profitability is also individual for each group of people belonging to the same sociotype.

\section{Discussion}

To summarize the assessment of the consumer profile in terms of typology. The strategy of motivating the consumer and maintaining his loyalty to the product or brand will be very different for a judging and prospecting sociotype. Therefore, the formation of selling texts must be done both judging sociotypes and prospecting. The difference in algorithms for assessing the quality of a product and its consumer properties will be different for sensory and intuitive types. The frequency of advertising should also be different for extroverted and introverted sociotypes in order to maximize consumer activation on the target action. Targeted action depends on a combination of thinking - ethics.

The semantic content of the content differs depending on the main typological function: thinking, ethics, intuition and sensory. Keyword analysis is shown in Table 1.

Table 1. Result of tag analysis from typological function.

\begin{tabular}{|c|l|}
\hline $\begin{array}{c}\text { Typological } \\
\text { function }\end{array}$ & \multicolumn{1}{|c|}{ Tags and keywords } \\
\hline Thinking & $\begin{array}{l}\text { system, analysis, measurement, parameter, technology, function, theory, } \\
\text { hypothesis, structure, practicality, instruction, resolution, classification, registry, } \\
\text { criterion, regularity, tool, model, synthesis, graph, formula, principle, scheme, }\end{array}$ \\
\hline
\end{tabular}




\begin{tabular}{|c|l|}
\hline & adequacy \\
\hline Ethics & $\begin{array}{l}\text { wonderful, amazing, cute, disgusting, ugly, mood, resentment, enthusiasm, } \\
\text { experience, sensitivity, contact, shyness, arrogance, enmity, hatred, enthusiasm, } \\
\text { envy, passion, protest, admiration, nonsense, charm, empathy, passion, courtesy, } \\
\text { the charm }\end{array}$ \\
\hline Intuition & $\begin{array}{l}\text { variability, process, foresight, future, past, error accounting, youth, old age, } \\
\text { forecast, course }\end{array}$ \\
\hline Sensing & $\begin{array}{l}\text { comfort, convenience, relaxation, rest, health, well-being, aesthetics, harmony, } \\
\text { physiological needs, discomfort }\end{array}$ \\
\hline
\end{tabular}

The semantic aggregation of content is also different for each sociotype. For example, a characteristic feature of content adaptation for INTP is the cause-effect relationships in images or schemes, whereas for ESTJ the structure of the presentation of information in the form of a table. When structuring static content, we can distinguish:

- structured sequential text (e.g. copywriting formula);

- factual text (for example, a set of loosely coupled facts about a product or product characteristics with their meanings);

- table with data (for example, a set of characteristics about a product);

- pivot table (for example, a comparison of two or more products);

- graphic schemes (for example, the sequence of actions during the operation of the product);

- associative images (for example, motivators or product exploitation images).

The classification of dynamic content can be considered as a combination of a static series of elements. Adaptation of each type of content to a sociotype is advisory in nature, therefore it is more profitable to operate not with a social type, but with a set of typological functions.

Thus, a possible method of organizing targeted advertising considering the sociotype is as follows:

An individualization of advertising content is created for each sociotype with a simple key action. Advertising is created only by a representative of his sociotype. Adaptation of advertising to a sociotype reduces its effectiveness.

Through sales channels, the user is offered successively different announcements, which determine the strength of feedback. Feedback force is an integral characteristic that considers how much, in relation to other advertisements shown to him, the user has completed the target action. According to the announcement with maximum feedback, a decision is made on whether the consumer belongs to the target group.

In the future, ads and content are displayed with a frequency adapted for introverted and extrovert types of personality.

Each subsequent announcement confirms, refines or refutes the starting hypothesis. To reduce the amount of equivalent content, you can focus on a bunch of rationality / irrationality and logic / ethics. The methods for determining the quality of the goods in this embodiment need to be alternated. Thus, when already 4 different ads are generated, you can achieve individualization of targeted advertising.

Targeting with this format of its construction can be considered as a function of teaching the consumer the pseudo-conscious choice of goods, in which the consumer agrees with the seller. This result is achieved due to the perception of information from the advertisement.

It should also be noted that the shorter the announcement, the more difficult it is to adapt to the sociotype and to adapt to the typological function. 


\section{Conclusion}

The proposed method for increasing the effectiveness of targeted advertising is passive. This method can be used to increase the loyalty of potential consumers. Increasing customer loyalty is achieved through the formation of psychologically adaptive content, which they perceive as a profitable offer. The main scope of application of this method is targeted advertising on social networks, as this sales channel is the main for many millions of potential consumers.

Considering psychological characteristics at the stage of content formation in digital sales is the most attractive area for the development of digital marketing.

Further studies on the use of adaptive content to shape the demand for a product are possible in studies of consumer reaction metrics on targeted advertising and the degree to which consumer reaction metrics influence the likelihood of a targeted action.

\section{References}

1. K. Govindan, Journal of Cleaner Production 227, 890 (2019)

2. S. France, Expert Systems with Applications 119, 456 (2019)

3. J. Müller, Computers in Human Behavior 96, 46 (2019)

4. J.F. Robles, Expert Systems with Applications 147, 113 (2020)

5. A. Osterwalder, The Business Model Ontology: a proposition in a design science approach (PhD thesis) (Université de Lausanne, Ecole des Hautes Etudes Commerciales, 2004)

6. J. Jankowski, The 16 Personality Types in a Nutshell (LOGOS MEDIA, 2016)

7. K. Pietrak, Cognitive Systems Research 47, 1 (2018)

8. A.V. Bataev, A.A. Gorovoy, A.B. Mottaeva, Proceedings of the 32nd International Business Information Management Association Conference, IBIMA 2018 - Vision 2020 (2018)

9. A.V. Bataev, A.A. Gorovoy, A.B. Mottaeva, Proceedings of the 32nd International Business Information Management Association Conference, IBIMA 2018 - Vision 2020 (2018)

10. I.E. Petrov, M.A. Zemtsov, The method of organizing the information flow in the learning and self-training process based on multi-content presentation structures. Patent (Russia, 2010)

11. A. Osterwalder, Y. Pigneur, Journal of the Association for Information Systems (2013) 